\title{
Retinal vein occlusion during flare of multicentric Castleman's disease
}

This article was published in the following Dove Press journal:

Clinical Ophthalmology

14 August 2013

Number of times this article has been viewed

\author{
Igor Kozak ${ }^{1,2}$ \\ Erin G Reid ${ }^{3}$ \\ 'King Khaled Eye Specialist Hospital, \\ Riyadh, Kingdom of Saudi Arabia; \\ ${ }^{2}$ University of California San Diego, \\ Jacobs Retina Center at the Shiley Eye \\ Center, La Jolla, CA, USA; ${ }^{3}$ University \\ of California San Diego, Moores \\ Cancer Center, AIDS Malignancy \\ Consortium, La Jolla, CA, USA
}

\begin{abstract}
We report a case of successive bilateral retinal vein occlusion in a human immunodeficiency virus (HIV)-positive male with multicentric Castleman's disease treated successfully with a single injection of intravitreal bevacizumab. Castleman's disease should be a differential diagnosis of occlusive retinovascular disease and, occasionally, ocular manifestation can lead to systemic diagnosis.
\end{abstract}

Keywords: retinal vein occlusion, Castleman's disease, intravitreal bevacizumab

\section{Introduction}

Castleman's disease is a rare lymphoproliferative disease characterized by massive growth of lymphoid tissue, with follicular hyperplasia, vascular proliferation, and plasmacytosis. The gold standard for diagnosis is lymph node biopsy. ${ }^{1}$ Three distinct histologic subtypes include the hyaline vascular type (usually unicentric and mild), the plasma cell type (often multicentric and aggressive), and the mixed-type. It can be confined to one site or can be multicentric associated with systemic symptomatology. Patients with multicentric Castleman's disease (MCD) present with multiple lesions, potentially affecting all organs, lymph nodes, liver, and spleen accompanied by constitutional symptoms and hematologic abnormalities. Multicentric Castleman's disease is the rarest form of disease at all ages but is the most frequent form present in the setting of human immunodeficiency virus (HIV) seropositivity. We herein report a case of retinal vein occlusion during flare of MCD complicated by macular edema that completely resolved after a single intravitreal injection of anti-angiogenic agent.

\section{Case report}

A 63-year-old active male cyclist with HIV (CD4 377/viral load $<48$ copies/mL) presented with blurred vision and light sensitivity in his left eye for several days while experiencing a flare of MCD disease with fever, tender lymphadenopathy, and profound fatigue. The patient had a history of right eye central retinal vein occlusion with vitreous hemorrhage resulting in significant permanent vision loss 4 years previously. Near that time he initially developed recurrent fevers, he also had cytopenias, hepatosplenomegaly, and tender lymphadenopathy that eventually led to diagnosis of MCD confirmed by lymph node biopsy. The patient declined recommended therapy with rituximab due to share of cost and prolonged remissions between flares. Initiation of valganciclovir 1 -year ago resulted in attenuation and reduced frequency of MCD flares. On examination, his visual acuity was 20/200 in the right eye and 20/100 in the left eye. Intraocular
Correspondence: Igor Kozak Vitreoretinal Division, King Khaled Eye Specialist Hospital, PO Box 7191, Riyadh I 1462, Kingdom of Saudi Arabia Tel +966 482 I 234 ext 3772

Email ikozak@kkesh.med.sa 

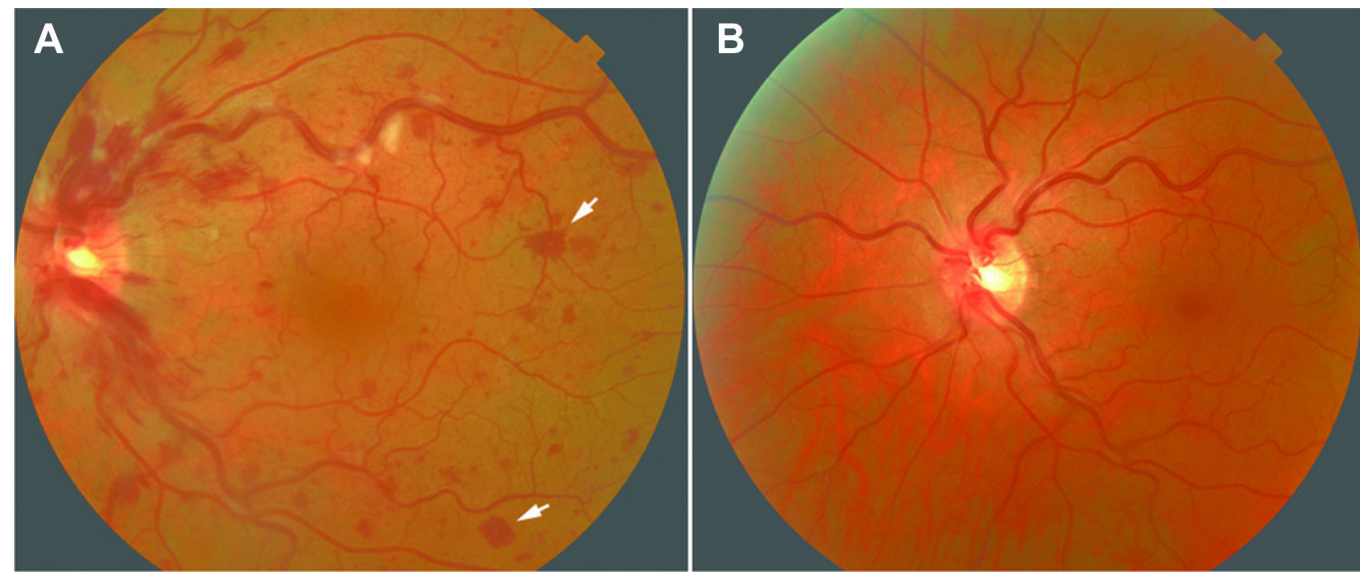

Figure I Color fundus photograph of the left eye of the patient with flare of multicentric Castleman's disease.

Notes: (A) At presentation, the eye showed mild optic nerve swelling, tortuous veins, cotton-wool spots, intraretinal hemorrhages, and Roth spots (white arrows). (B) Five months after intravitreal injection of bevacizumab there is resolution of all pathologic findings.

pressure in both eyes and blood pressure were normal. Retinal examination in the right eye showed macular atrophy and laser burns after panretinal photocoagulation. The fundus exam of the left eye revealed optic nerve swelling, tortuous veins, cotton-wool spots, and intraretinal hemorrhages, a few of which were white-centered Roth spots (white arrows on Figure 1). Fluorescein angiography and spectral-domain optical coherence tomography (SD-OCT) showed delayed perfusion times and macular edema in the left eye, respectively. SD-OCT showed subretinal fluid extending from the optic disc to the fovea (Figure 2). Hypercoagulability workup demonstrated only mildly increased anti-cardiolipin antibody; there was no evidence of a lupus anticoagulant, prothrombin, or factor $\mathrm{V}$ Leiden mutation and the patient had normal antithrombin, protein $\mathrm{C}$, and $\mathrm{S}$. His left eye was treated with intravitreal injection of bevacizumab $1.25 \mathrm{mg}$ in $0.05 \mathrm{~mL}$. After a single injection there was a rapid improvement in visual acuity in his eye. At the last visit 6 months after treatment his visual acuity remained at 20/20 with normal retinal findings (Figure 2). He also initially received the recommended systemic therapy with rituximab followed by high dose zidovudine with valganciclovir; this resulted in the longest remission to date of systemic MCD flare ( $>12$ months to date).

\section{Discussion}

MCD affects primarily neck, thoracic, and retroperitoneal lymph nodes. Ophthalmic complications in MCD are very rare with most published cases describing intraorbital and optic nerve lesions. ${ }^{2,3}$ Intraocular involvement is rarer with one
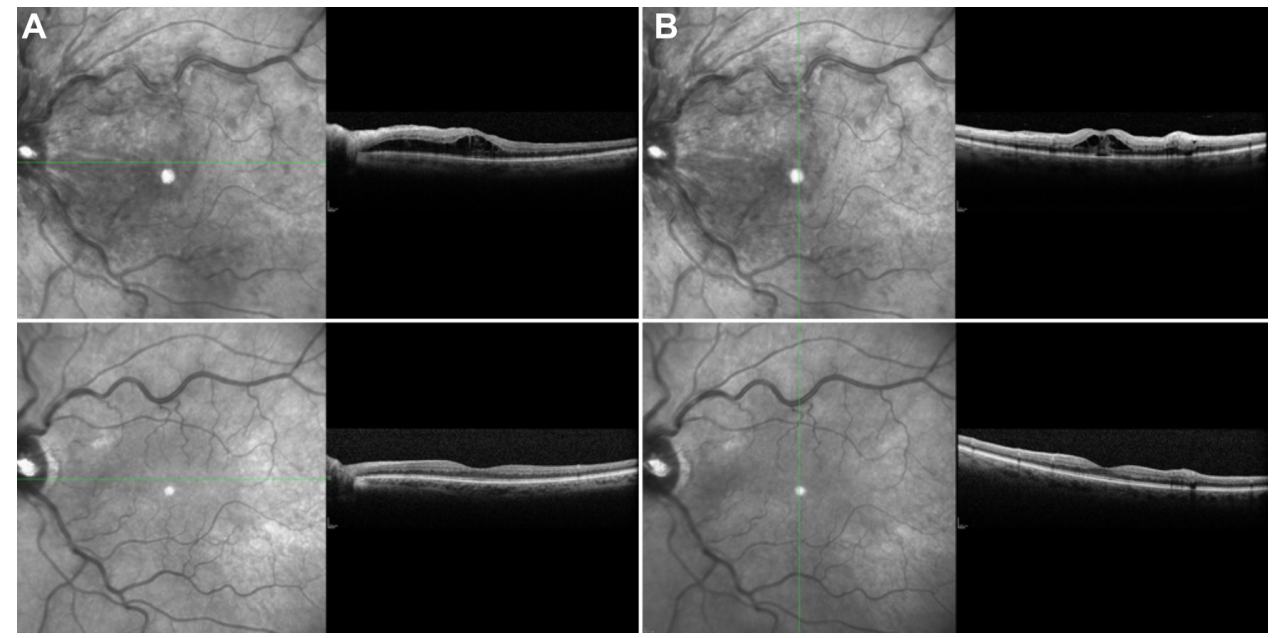

Figure 2 Horizontal (A) and vertical (B) scans of eye at presentation showing subretinal fluid extending from the optic disc to the fovea. Corresponding follow-up scans (lower panels) 5 months after treatment showing complete resolution of subretinal fluid. 
published adult case of uveitis, ${ }^{4}$ two cases of bilateral, ${ }^{5,6}$ one case of unilateral serous retinal detachment and choroidal effusion, ${ }^{7}$ one case of hypertensive choroidopathy, ${ }^{8}$ one case of choroidal infiltrates, ${ }^{7}$ and one case of optic nerve drusen and peripapillary choroidal neovascularization in a patient with peripheral neuropathy, organomegaly, endocrinopathy, monoclonal gammopathy, skin changes (POEMS) syndrome and associated Castleman's disease. ${ }^{9}$ One pediatric case describing venous engorgement and tortuosity, intraretinal hemorrhages, cotton wool spots, and neurosensory detachment of the posterior pole was thought to be due to hyperviscosity syndrome which responded to one session of plasmapheresis. ${ }^{10}$ Herein, we report a case of an incomplete vein occlusion in an HIV+ adult patient. Central retinal vein occlusion in the other eye triggered medical evaluation leading to diagnosis of MCD. Patients with HIV infection have been reported to have a small risk of retinal vascular occlusion ${ }^{11}$ but because the occlusion occurred in both eyes during flares of lymphoproliferative disease we attribute this event to MCD. A single injection of an anti-angiogenic agent was sufficient for resolution of subretinal fluid and improvement in vision. Finding Roth spots in the retina in MCD is also unique and to our knowledge not previously reported.

After an automated search in PubMed, this appears to be the first case of successive bilateral retinal vein occlusion in an HIV+ male with MCD treated successfully with a single injection of intravitreal bevacizumab. Castleman's disease should be on differential diagnosis of occlusive retinovascular disease and, occasionally, ocular manifestation can lead to systemic diagnosis.

\section{Disclosure}

The authors report no conflicts of interest in this work.

\section{References}

1. Castleman B, Iverson L, Menendez VP. Localized mediastinal lymphnode hyperplasia resembling thymoma. Cancer. 1956;9(4):822-830.

2. Kurokawa T, Suzuki S, Kawaguchi K, Fujisawa N, Yoshimura N. Castleman disease presenting with ophthalmic signs and symptoms. Am J Ophthalmol. 1999;128(1):114-116.

3. Inatani M, Kashii S, Nosaka K, Arima N. Orbital pseudotumor as an initial manifestation of multicentric Castleman's disease. Jpn $J$ Ophthalmol. 2005;49(6):505-508.

4. Oshitari T, Kajita F, Tobe A, et al. Refractory uveitis in patient with castleman disease successfully treated with tocilizumab. Case Rep Ophthalmol Med. 2012;2012:968180.

5. Park SH, Song SJ. Castleman's disease presenting with uveal effusion syndrome. Korean J Ophthalmol. 2010;24(3):182-185.

6. Barile GR, Khatib N, Lee SE, Dhrami-Gavazi E, Iranmanesh R, Stokes MB. Exudative retinal detachment in Castleman disease. Retina Cases and Brief Reports. 2009;3(2):200-203.

7. Emerson GG, Lim L, Loriaux M, et al. Multicentric Castleman disease associated with ocular involvement. A clinicopathologic case report. Retina Cases and Brief Reports. 2009;3(2):197-199.

8. Liu DT, Shields JA, Li CL, Ng HK, Lam DS. Hypertensive choroidopathy in Castleman's disease. Graefes Arch Clin Exp Ophthalmol. 2011;249(12):1901-1903.

9. Diduszyn JM, Quillen DA, Cantore WA, Gardner TW. Optic disk drusen, peripapillary choroidal neovascularization, and POEMS syndrome. Am J Ophthalmol. 2002;133(2):275-276.

10. Jorge R, Scott IU, Oliveira RC, Costa RA, Siqueira RC, LouzadaJúnior P. Ocular findings in a patient with Castleman's disease before and after treatment with immunosuppression and plasmapheresis. Ophthalmic Surg Lasers Imaging. 2010;41 Online.

11. Dunn JP, Yamashita A, Kempen JH, Jabs DA. Retinal vascular occlusion in patients infected with human immunodeficiency virus. Retina (Philadelphia, Pa). 2005;25(6):759-766.
Clinical Ophthalmology

\section{Publish your work in this journal}

Clinical Ophthalmology is an international, peer-reviewed journal covering all subspecialties within ophthalmology. Key topics include: Optometry; Visual science; Pharmacology and drug therapy in eye diseases; Basic Sciences; Primary and Secondary eye care; Patient Safety and Quality of Care Improvements. This journal is indexed on

\section{Dovepress}

PubMed Central and CAS, and is the official journal of The Society of Clinical Ophthalmology (SCO). The manuscript management system is completely online and includes a very quick and fair peer-review system, which is all easy to use. Visit http://www.dovepress.com/ testimonials.php to read real quotes from published authors. 